\title{
Characterization of the immune response of cattle against non-cytopathic and cytopathic biotypes of bovine viral diarrhoea virus
}

\author{
Michel Lambot, Alain Douart, † Eliane Joris, $\ddagger$ Jean-Jacques Letesson§ and Paul-Pierre Pastoret \\ Department of Immunology/Vaccinology, Faculty of Veterinary Medicine, University of Liège, B43bis, B-4000 Sart Tilman-Liège, Belgium
}

Cross-infection studies of normal calves infected with homologous pairs of non-cytopathic and cytopathic bovine viral diarrhoea virus (BVDV) showed significant differences in both humoral and cellmediated immune responses against either biotype over a period of 5 months. Serological assays after primary intranasal inoculation showed striking significant $(P<0.05)$ differences between biotypes. Neutralizing titres were detected earlier and were much higher with the non-cytopathic strain than with the homologous cytopathic strain. Significant biotype-specific differences were also observed in the lymphocyte proliferative responses of cattle following in vitro stimulation by non-cytopathic/ cytopathic BVDV and the non-structural $\mathrm{p} 80$ protein (NS3). The secondary immune response seems to be largely influenced by the biotype used for the primary inoculation and only to a lesser extent by the biotype inoculated for the second time after an interval of 91 days. Animals exposed twice to the cytopathic biotype, which exhibited the lowest antibody titres, showed evidence of BVDV-specific cellmediated immunity as measured by lymphoproliferation against BVDV. In contrast, the antibody response in the subgroup of animals inoculated twice with homologous non-cytopathic virus was inversely correlated with the proliferative responses. These differences in the immune response were not readily apparent for the two other remaining subgroups which had received cytopathic or non-cytopathic biotypes alone following the second inoculation with non-cytopathic or cytopathic viruses, respectively. Taken together, these data suggest that the differences in immune responses against cytopathic or non-cytopathic strains may be due to a Th1/Th2-like regulatory mechanism.

\section{Introduction}

Bovine viral diarrhoea virus (BVDV) is a member of the genus Pestivirus within the family Flaviviridae (Westaway et al., 1985). It is antigenically related to border disease virus of sheep and hog cholera virus (classical swine fever virus) of pigs. BVDV is distributed worldwide and is considered to be one of the most important viral pathogens of cattle although swine

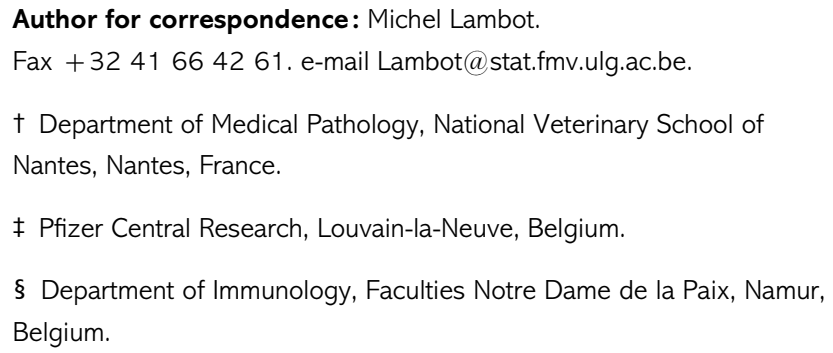

and other ruminants are also susceptible (for a review see Paton, 1995).

Field BVDV isolates can be categorized into cytopathic or non-cytopathic biotypes according to their behaviour in cell culture (Baker, 1987; Adler et al., 1994) and by the genomic rearrangements in the non-structural p125/p80 gene. The cytopathic biotype invariably expresses the NS3 protein, either by introducing a cleavage site in the NS23 protein expressed by the non-cytopathic biotype, or by duplication of the NS23 sequence encoding the NS3 protein (Donis \& Dubovi, 1987a). Strains of the non-cytopathic biotype are routinely isolated from cases of acute infection and are invariably present in calves born persistently viraemic because of early transplacental infection (Liess et al., 1974; McClurkin et al., 1984). Such persistently infected animals generally succumb to fatal mucosal disease as a result of a natural superinfection with the cytopathic biotype derived from 
mutation of a persistent non-cytopathic strain (Brownlie et al., 1987). This origin of the cytopathic virus explains the high level of antigenic similarity between a cytopathic/noncytopathic virus pair isolated from the same animal (Howard et al., 1987). It is generally accepted that humoral immunity plays a major role in protection against the disease. In experimental infection with BVDV, protection can be conferred through adoptive transfer of antibody to immunologically naive animals (Howard et al., 1989; Shope et al., 1976). Furthermore, cattle are considered to be immune to re-infection following their recovery from infection and the accompanying neutralizing antibody response (Pritchard, 1963). However, the roles played by either the non-cytopathic and/or cytopathic biotypes separately or interactively in the host's humoral immune response during the course of infection have not been investigated. Similarly, the impact and the role of the cellular immune response to BVDV in cattle have also not been studied in depth except for a few in vitro studies (Larsson \& Fossum, 1992; Hooper et al., 1992; Howard et al., 1992). In these studies, where blood lymphocytes from seropositive animals were used, it was suggested that $\mathrm{BoCD} 4^{+}$cells play a pivotal role in the establishment of the immune memory to BVDV.

In this present report, we have attempted to characterize the immune response of cattle by comparing the qualitative and quantitative differences to a pair of non-cytopathic and cytopathic viruses in cross-infection studies by examination of the neutralizing antibody profiles and $\mathrm{T}$ cell proliferation. We also explored the proliferative response of cattle lymphocytes to a recombinant NS3 protein, as a preliminary study for detailed characterization of $\mathrm{T}$ cell recognition of BVDV proteins. The significance of the BVDV-specific immune responses reported here could be in their predictive value in assessment of natural or artificial protection against BVDV field virus infections.

\section{Methods}

Cells and viruses. An homologous pair of non-cytopathic and cytopathic strains, Pe 515, originally isolated at the AFRC Institute for Research on Animal Diseases, Compton, UK (Brownlie et al., 1984) was kindly supplied by J. Brownlie, Royal Veterinary College, North Mimms, UK. The non-cytopathic strain was purified three times by terminal dilution while the cytopathic strain was plaque purified three times. The viruses were grown in calf testis (CT) cell cultures which were free of adventitious BVDV and maintained in OptiMEM medium (Gibco) supplemented with $10 \%$ heat-inactivated foetal calf serum treated with $\beta$ propiolactone. The non-cytopathic Pe 515 virus preparation was obtained after 5 days in culture by one freeze-thawing cycle and centrifugation at 3000 r.p.m. for $10 \mathrm{~min}$ to remove large cellular debris. The supernatant was then frozen at $-80^{\circ} \mathrm{C}$ in aliquots until used for inoculation of calves and in in vitro assays. For the cytopathic Pe 515 virus preparation, BVDVinfected monolayers were prepared similarly and were harvested when $75 \%$ of cells showed a cytopathic effect. The supernatant from a noninfected CT cell culture, grown under similar conditions and treated as were the infected ones, was used as control. Titrations of viruses were

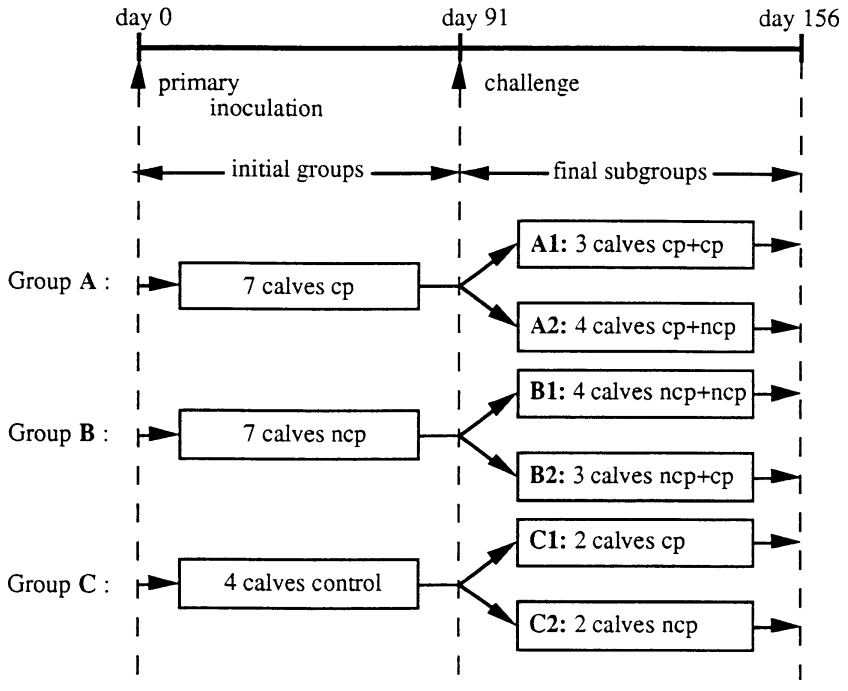

Fig. 1. Schematic representation of the inoculation procedure. Animals were divided into three groups in isolation units for the primary inoculation (at day 0) and were allotted to two isolation units for the challenge procedure at day 91 . Based on their inoculation histories, all animals were divided into six subgroups: two subgroups in primary infection ( $\mathrm{C} 1$ and $\mathrm{C} 2$ ) and four subgroups in challenge (A1-2 and B1-2). Arrows indicate time of both primary and secondary inoculations.

made in CT cell cultures and the $\mathrm{TCID}_{50}$ was calculated according to Reed \& Muench (1938). Non-cytopathic virus was detected by an immunofluorescent method.

Experimental design. A total of 18 calves, about 3 months old, which were both BVD virus- and BVDV-antibody negative were randomly allotted to two groups of seven (A and B) and one group of four $(C)$ and housed in isolation units prior to primary inoculation. Animals were inoculated intranasally by spraying into each nostril $5 \mathrm{ml}$ of culture medium containing $10^{6} \mathrm{TCID}_{50}$ of virus $/ \mathrm{ml}$ of the cytopathic (group A) and the homologous non-cytopathic (group B) Pe 515 strain. Animals in group $\mathrm{C}$, used as negative controls, were each intranasally inoculated with virus-free cell culture medium.

Ninety-one days after inoculation, all calves were allotted to two isolation units and intranasally challenged with non-cytopathic or cytopathic Pe 515 strains as indicated in Fig. 1. The doses of inocula were the same as in primary inoculation. In the first unit, two control calves (group C), three calves from group A and three calves from group B were challenged with cytopathic BVDV. In the second unit, the remaining calves received the non-cytopathic counterpart of the BVDV strain used. Of these, two animals were from group $C$, four animals from group $A$ and four from group $B$.

Blood samples were collected on the day of challenge and at 3 to 7 day intervals thereafter for a period of 10 weeks.

Preparation of recombinant BVDV NS3 protein. Construction and characterization of recombinant BVDV Osloss strain NS3 protein were recently described (Vanderheijden et al., 1993). Briefly, the NS3 gene isolated from $\mathrm{NcoI}-\mathrm{BamHI}$-restricted pARNS3 was inserted into the pACYMI transfer vector. Spodoptera frugiperda insect cells (SF9) were cotransfected with the resulting pACYNS3 and wild-type Autographa californica nuclear polyhedrosis virus (AcNPV) DNA. For proliferation assays, recombinant NS3 antigen was produced from an AcNPVNS3infected SF9 cell pellet which was lysed by three cycles of freeze-thawing, followed by sonication for $3 \times 10 \mathrm{~s}$, filtration through a $0 \cdot 22 \mu \mathrm{m}$ pore size 
filter (Nalgene) and storage at $-70^{\circ} \mathrm{C}$ until used. The identity of the NS3 protein and its purity (data not shown) were established as described by Vanderheijden et al. (1993).

Neutralization assay. The neutralizing activity of serum samples against 100 p.f.u. of cytopathic Pe 515 virus was determined by a microneutralization test (Lobmann et al., 1986) with a few modifications. Neutralization titres are expressed as the reciprocal of the highest dilution resulting in a $50 \%$ reduction of BVDV plaques relative to the virus control.

Lymphocyte proliferation assay. Peripheral blood mononuclear cells (PBMC) were prepared on Ficoll-Hypaque (Pharmacia) as described by Letesson et al. (1985). PBMC were cultured in round-bottomed plates (Nunc) at 2.0 $\times 10^{5}$ cells per well in RPMI 1640 medium supplemented with $10 \%$ heat-inactivated foetal calf serum, $1 \mathrm{mM}$ sodium pyruvate, $2 \mathrm{mM}$ glutamine, $25 \mathrm{mM}$ HEPES, $50 \mu \mathrm{M}$ 2-mercaptoethanol (2-ME), $0.5 \mu \mathrm{M}$ amphotericin B, $100 \mathrm{IU} / \mathrm{ml}$ penicillin and $100 \mu \mathrm{g} / \mathrm{ml}$ streptomycin.

The proliferative responses against non-cytopathic Pe 515 virus ( $1 \cdot 0$ $\mathrm{TCID}_{50}$ per cell), the homologous cytopathic Pe 515 virus $\left(0.5 \mathrm{TCID}_{50}\right.$ per cell) and the recombinant BVDV NS3 protein were determined in sets of six wells. Cultures were incubated for 6 days at $37{ }^{\circ} \mathrm{C}$ in $5 \% \mathrm{CO}_{2}$ and pulsed with $\left[\right.$ methyl $\left.{ }^{3} \mathrm{H}\right]$ thymidine $(0 \cdot 8 \mu \mathrm{Ci}$; sp. act. $2 \mathrm{Ci} / \mathrm{mmol})$ (Amersham) for the last $18 \mathrm{~h}$ of culture. The cells were harvested onto glass filters with an automated cell harvester (Skatron) and the radioactivity on the filters was estimated with a scintillation counter (Betaplate 1205, Wallac). Non-infected CT cell culture at a similar dilution was used as a control. Results were expressed as a stimulation index (mean c.p.m. test sample/mean c.p.m. control). In the proliferation assays with soluble recombinant NS3 protein, a similar dilution of a filtrate from wild baculovirus-infected SF9 cells was used as a control. To control specificity, PBMCs from a BVDV-negative calf were included in all proliferation assays, and the stimulation index for each day over the period of the experiment was less than two in all cases (data not shown).

Analysis of data. Differences in neutralizing antibody and cellular responses between subgroups were analysed for statistical significance by Student's $t$-test.

\section{Results}

\section{Antibody responses following BVDV inoculation}

The pattern of development of neutralizing antibody within each of the six subgroups is shown in Fig. 2. The four control calves (C1 and C2), which had no antibody when exposed to BVDV, developed neutralizing antibody response with titres which were at least 1500 fold (Fig. 2). However, there was a significant difference between the kinetics of the antibody responses in calves inoculated with non-cytopathic virus and in those which received the cytopathic counterpart. Neutralizing activity was clearly detectable 1 week earlier in subgroup C2 than in subgroup $\mathrm{CI}$ and the antibody response which was then reached was significantly higher $(P<0.05)$ in $C 2$ compared with $\mathrm{C} 1$ for the remainder of the experiment. In the four other subgroups, challenge had no noticeable effect on the antibody response, regardless of the biotype used (Fig. 2). In terms of overall titres, calves first inoculated with noncytopathic virus (B1 and B2) showed higher levels of neutralizing antibody than those which initially received 'homologous' cytopathic virus (A1 and A2), regardless of the biotype used in the challenge. However, these higher levels were only significant $(P<0.05)$ in the subgroup of animals inoculated twice with non-cytopathic virus (B1).

\section{Lymphoproliferative response to BVDV}

In a preliminary assay, the optimum virus dose for proliferation of PBMC stimulated with either biotype of strain Pe 515 was $1 \cdot 0 \mathrm{TCID}_{50}$ per cell for the non-cytopathic virus and $0.5 \mathrm{TCID}_{50}$ per cell for its cytopathic counterpart (data not shown). Furthermore, maximum stimulation was induced using live virus preparations in cultures with $50 \mu \mathrm{M} 2-\mathrm{ME}$ and was observed at day 6 of proliferation (data not shown).

Fig. 3 shows the BVDV-specific proliferative responses in the six subgroups of calves after experimental inoculation. On primary inoculation with BVDV, significant $(P<0.005)$ cellular reactivity to virus was generated at 3 weeks, regardless of the biotype used ( $\mathrm{C} 1$ and $\mathrm{C} 2$ ). The responsiveness to virus of the subgroups ncp and cp did not differ, either in the pattern or magnitude of proliferation. In contrast, a second inoculation 91 days after the first did not significantly affect the proliferative memory responses to virus in any subgroup of BVDV-immune calves (AI-2 and BI-2). At the time of challenge there was, however, a notable difference in the responses between subgroups depending on whether they had received the noncytopathic or cytopathic biotype as a primary inoculum. The mean stimulation index for each subgroup given cytopathic virus first (A1 and A2) was significantly higher $(P<0.05)$ at day 91 than that of the two subgroups which were given noncytopathic virus first (B1 and B2). Although the response fluctuated from week to week, this trend was consistent over the 10 week period of the experiment.

It should be noted that the pattern of the proliferative response of any subgroup to the cytopathic virus preparation closely resembled that induced by the non-cytopathic preparation although the magnitude of the responses was not as great as that seen with the non-cytopathic virus.

\section{Response to recombinant BVDV NS3 protein}

The lymphoproliferative response of calves to Osloss strain NS3 protein was tested at 1:30, 1:60 and $1: 150$ dilution of antigen. Fig. 4 shows the proliferation obtained at the optimum dose of $1: 60$ and indicates that recombinant NS3 protein was significantly recognized $(P<0.05)$ by lymphocytes from five of the six subgroups of calves (AI-2, BI and C1-2). The magnitude of the responses was largely dependent on the biotype used at the last inoculation of the challenge experiment. A higher response was observed with lymphocytes from the subgroups of animals inoculated with non-cytopathic virus (A2, B1 and C2), compared with the response obtained in any subgroup exposed to the cytopathic counterpart (A1, B2 and $(1)$. 


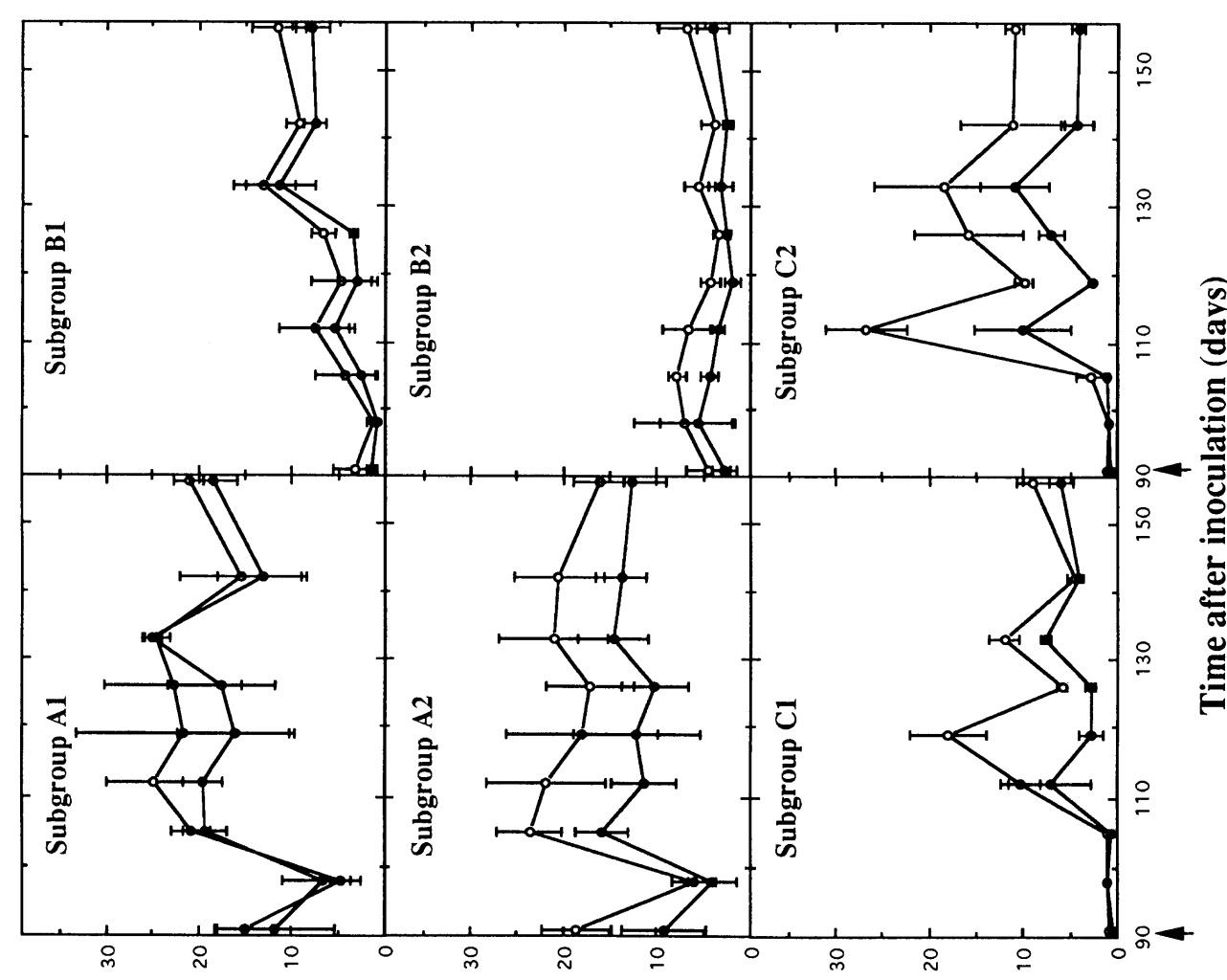

хәри! ио!ฺ|пu!ฺ

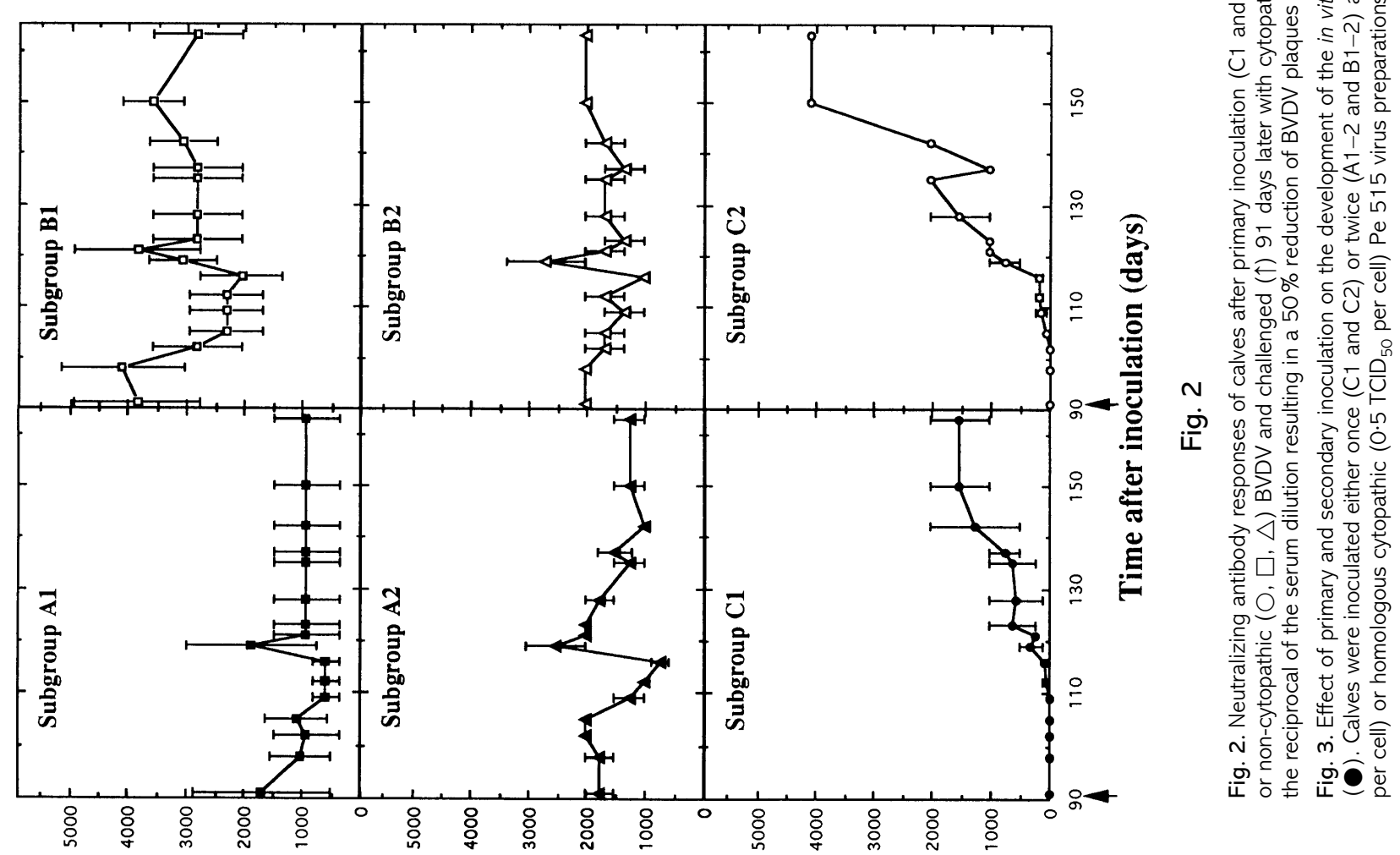

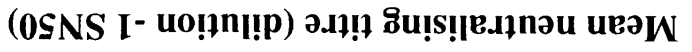




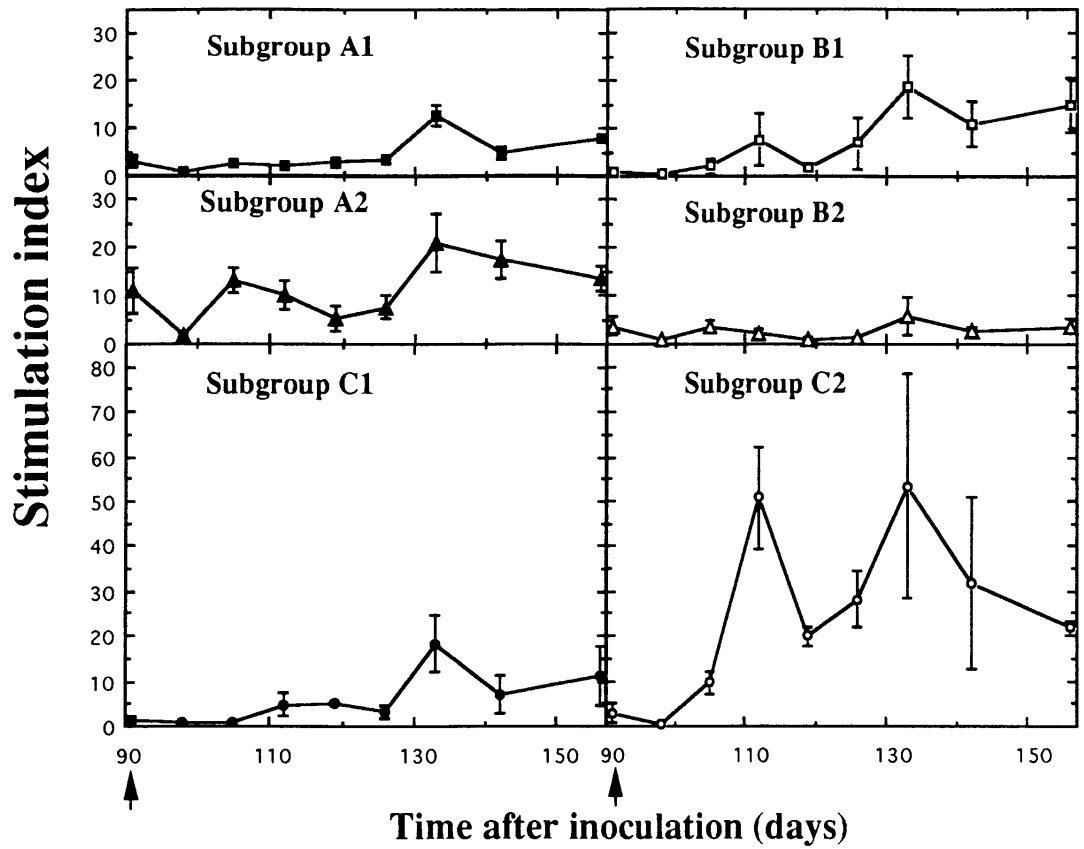

Fig. 4. Comparison of the in vitro lymphocyte proliferative response of calves to recombinant NS3 protein after primary inoculation and after challenge. Calves were inoculated either once ( $\mathrm{C} 1$ and $\mathrm{C} 2$ ) or twice (A1-2 and B1-2) according to the procedure described in Fig. 1. Arrows indicate time of both primary inoculation and challenge. PBMC were cultured with recombinant NS3 protein at 1:60 dilution. Proliferation is expressed as a stimulation index.

\section{Discussion}

In the present study, we chose to investigate the characteristics of the immune response of calves post-natally infected with a well-characterized pair of cytopathic and non-cytopathic BVDV strains (Pe 515) which were originally derived from a single animal (Brownlie et al., 1984).

By sero-neutralization, it was first shown that the noncytopathic biotype induced in the experimental animals a significantly more rapid and superior primary antibody response than the homologous cytopathic biotype. These higher neutralizing titres were maintained after the second inoculation, whatever biotype was used in the challenge. An inference drawn from the antibody response to BVDV is that biotype differences alone might result in differential humoral responses for the same virus strain pair. However, it will be essential to establish whether these effects observed with strain pair Pe 515 can be extended to other cytopathic and noncytopathic strains. Previous investigations (House \& Manley, 1973; Shope et al., 1976; Howard et al., 1989) emphasized the importance of immunoglobulins as mediators of immunity in BVDV re-infection. In contrast, cell-mediated immunity, known to be crucial in aiding recovery from many virus infections, has not been studied in depth for BVDV. For the pestivirus hog cholera virus, Rümenapf et al. (1991) showed that vaccinated animals with no neutralizing antibody titres often resist virus challenge, suggesting the involvement of mechanisms of protection other than antibodies.

Lymphocyte proliferation driven by specific antigen has been used as a means to define cellular reactivity to BVDV infection. On primary inoculation in calves, it has been shown that it is possible to induce memory $\mathrm{T}$ cells capable of responding to a BVDV stimulation in vitro. The time-course of this response is similar to that seen in many other acute virus infections of young calves, contrary to the slow response in BVDV-specific antibody titres. There was no notable difference between both biotypes in the magnitude of the stimulation index obtained in the proliferation assays. The cellular response to challenge seems to be largely influenced by the biotype used in the primary exposure and only to a lesser extent by the biotype inoculated the second time. Lymphocyte reactivity of animals exposed to a cytopathic biotype at the first inoculation is significantly higher $(P<0.05)$ throughout the duration of the secondary response as compared to that of calves initially exposed to a non-cytopathic biotype.

Taken together, the data presented here highlight a difference in immune recognition by BVDV-infected animals, indicating that this recognition depends on the biotype of the strain pair involved. Hence, animals exposed at first to the noncytopathic biotype, which exhibited significantly higher antibody titres, show a low secondary proliferative response against the virus whatever the biotype used in the secondary inoculation. In contrast, animals initially inoculated with the homologous cytopathic biotype have a high $\mathrm{T}$ cell reactivity during the secondary exposure to cytopathic or noncytopathic viruses, despite the lower level of neutralizing activity seen in these calves. This distinction between humoral and cell-mediated responses would suggest the existence of distinct Th1 and Th2 subpopulations in the regulation of specific immune responses to BVDV, as recently described for bovine parasitic diseases (Brown et al., 1994; Tetzlaff et al., 1992). In order to determine the validity of the Th1/Th2 hypothesis, we are investigating the constitutive expression of two groups of cytokines, typical of the Th1 or Th2 cytokine 
phenotypes, in cells isolated from a much larger group of calves infected with either biotype of BVDV.

The fact that non-structural proteins can be involved in the induction of cell-mediated responses and in resistance to infection (Gibson et al., 1988) led us to examine in vitro $\mathrm{T}$ cell proliferative responses to NS3, one of the major non-structural polypeptides of BVDV. In this study, recombinant Osloss strain NS3 protein was recognized by lymphocytes from five of six experimental subgroups while non-cytopathic or cytopathic virus preparations were recognized in all calves infected. This suggests that other viral proteins may be important targets of $\mathrm{T}$ cell reactivity. It also suggests that while NS3 protein is an immunodominant antigen in the antibody responses of immunized calves (Donis \& Dubovi, 1987b), this may not be true for $\mathrm{T}$ cell responses. Moreover, the subgroups of animals which received the non-cytopathic virus at the last inoculation developed the highest proliferative responses when compared with calves whose last inoculation was with cytopathic virus; the nature of the relationship between the ability to mount a $\mathrm{T}$ cell response to NS3 protein and the inoculation regime is not well understood. One may hypothesize that differences in the mode of interaction of the BVDV biotypes with host cells, related or not to a differential tissue tropism, could be the origin of the variation in the frequency of NS3-specific responder cells.

In conclusion, we have simultaneously evaluated the antibody and $\mathrm{T}$ cell responses of calves to two different biotypes of the same virus. Qualitative and quantitative differences in the immune response were demonstrated. Before drawing definite conclusions about the ability of BVDV biotypes to induce a differential immune mechanism, a final experimental infection with other pairs of cytopathic and noncytopathic viruses should be combined with analysis of the expression of cytokines strictly limited to Th1- or Th2-type responses. If correct, the Th1/Th2 hypothesis will have important implications for vaccination against BVDV.

The authors wish to thank M. Loncar for skilful technical assistance and express their gratitude to Drs M. Denis, P. Hubert and J. Lyaku for helpful discussions and for reviewing the manuscript.

This work was supported by grants from the 'Institut pour l'encouragement de la Recherche Scientifique dans l'Industrie et l'Agriculture' (IRSIA)

\section{References}

Adler, H., Perterhans, E. \& Jungi, T. W. (1994). Generation and functional characterization of bovine bone marrow derived macrophages. Veterinary Immunology and Immunopathology 41, 211-227.

Baker, J. C. (1987). Bovine viral diarrhea virus: a review. Journal of the American Veterinary Medical Association 190, 1449-1458.

Brown, W. C., Davis, W. C., Dobbelaere, D. A. E. \& Rice-Ficht, A. C. (1994). CD4 + T-cell clones obtained from cattle chronically infected with Fasciola hepatica and specific for adult worm antigen express both unrestricted and Th2 cytokine profiles. Infection and Immunity 62, 818-827.
Brownlie, J., Clarke, M. C. \& Howard, C. J. (1984). Experimental production of fatal mucosal disease in cattle. Veterinary Record 2, 535-536.

Brownlie, J., Clarke, M. C. \& Howard, C. J. (1987). Clinical and experimental mucosal disease - defining a hypothesis for pathogenesis. In Pestivirus Infections of Ruminants, pp. 147-157. Edited by J.W. Harkness. CEC Seminar, Brussels, September 1985.

Donis, R. O. \& Dubovi, E. J. (1987 a). Differences in virus-induced polypeptides in cells infected by cytopathic and noncytopathic biotypes of bovine virus diarrhea-mucosal disease virus. Virology 158, 168-173.

Donis, R. O. \& Dubovi, E. J. (1987 b). Molecular specificity of the antibody responses of cattle naturally and experimentally infected with cytopathic and noncytopathic bovine viral diarrhea virus biotypes. American Journal of Veterinary Research 48, 1549-1554.

Gibson, C. A., Schlesinger, J. J. \& Barrett, A. D. T. (1988). Prospects for a virus non-structural protein as a subunit vaccine. Vaccine 6, 7-9.

Hooper, L. B., Clarke, M. C. \& Brownlie, J. (1992). Lymphocyte proliferation in response to bovine viral diarrhoea virus antigen. Proceedings of the Second Symposium on Pestivirus, pp. 131-135, Annecy, France, 1-3 October.

House, J. A. \& Manley, M. (1973). Comments on passive immunity to bovine viral diarrhea. Journal of the American Veterinary Medical Association 163, 819-820.

Howard, C. J., Clarke, M. C. \& Brownlie, J. (1987). Comparisons by neutralisation assays of pairs of non-cytopathogenic and cytopathogenic strains of bovine virus diarrhoea virus isolated from cases of mucosal disease. Veterinary Microbiology 13, 361-369.

Howard, C. J., Clarke, M. C. \& Brownlie, J. (1989). Protection against respiratory infection with bovine virus diarrhoea virus by passively acquired antibody. Veterinary Microbiology 19, 195-203.

Howard, C. J., Clarke, M. C., Sopp, P. \& Brownlie, J. (1992). Immunity to BVDV in calves: the role of different T-cell subpopulations analysed by specific depletion in vivo with monoclonal antibodies. Veterinary Immunology and Immunopathology 32, 303-314.

Larsson, B. \& Fossum, C. (1992). Bovine virus induces in vitro a proliferative response of peripheral blood mononuclear cells from cattle immunized by infection. Veterinary Microbiology 31, 317-325.

Letesson, J.-J., Lostrie-Trussart, N. \& Depelchin, A. (1985). Production d'anticorps monoclonaux spécifiques d'isotypes d'immunoglobulines bovines. Annales de Médecine Vétérinaire 129, 131-141.

Liess, B., Frey, H.-R., Kittsteiner, H., Baumann, F. \& Neumann, W. (1974). Observations and investigations on mucosal disease of cattle, a late stage of BVD-MD virus infection with immunobiological explanation and criteria of a slow virus infection. Deutsche Tierärztliche Wochenschrift 81, 481-487.

Lobmann, M., Charlier, P., Florent, G. \& Zygraich, N. (1984). Clinical evaluation of a temperature-sensitive bovine viral diarrhea vaccine strain. American Journal of Veterinary Research 45, 2498-2503.

McClurkin, A. W., Littledike, E. T., Cutlip, R. C., Frank, G. H., Coria, M. F. \& Bolin, S. R. (1984). Production of cattle immunotolerant to BVD virus. Canadian Journal of Comparative Medicine 48, 156-161.

Paton, D. J. (1995). Pestivirus diversity. Journal of Comparative Pathology 112, 215-236.

Pritchard, W. R. (1963). The bovine viral diarrhea-mucosal disease complex. Advances in Veterinary Science 8, 1-47.

Reed, L. J. \& Muench, H. (1938). A simple method of estimating fifty percent endpoints. American Journal of Hygiene 27, 493-497.

Rümenapf, T., Stark, R., Meyers, G. \& Thiel, H.-J. (1991). Structural proteins of hog cholera virus expressed by vaccinia virus: further 
characterization and induction of protective immunity. Journal of Virology 65, 586-597.

Shope, R. E., Muscoplat, C. C., Chen, A. W. \& Johnson, D. W. (1976). Mechanism of protection from primary bovine viral diarrhea virus infection. I. The effects of dexamethasone. Canadian Journal of Comparative Medicine and Veterinary Science 40, 355-359.

Tetzlaff, C. L., Rice-Ficht, A. C., Woods, V. M. \& Brown, W. (1992). Induction of proliferative responses of $\mathrm{T}$ cells from Babesia bovis-immune cattle with a recombinant 77 -kilodalton merozoite protein $(\mathrm{Bb}-1)$. Infection and Immunity 60, 644-652.
Vanderheijden, N., De Moerlooze, L., Vandenbergh, D., Chappuis, G., Renard, A. \& Lecomte, C. (1993). Expression of the bovine viral diarrhoea virus Osloss p80 protein: its use as ELISA antigen for cattle serum antibody detection. Journal of General Virology 74, 1427-1431.

Westaway, E. G., Brinton, M. A., Gaidamovich, S. Ya., Horzinek, M. C., Igarashi, A., Kaariainen, L., Lvov, D. K., Porterfield, J. S. \& Trent, D. W. (1985). Togaviridae. Intervirology 24, 125-139.

Received 14 December 1995; Accepted 17 December 1996 